\title{
Avaliação do colágeno do tipo III na cicatrização de queimaduras em caprinos descornados por ferro quente e tratados com laser infravermelho
}

Carolina dos Anjos ${ }^{[a]}$, Bruna Stanigher Barbosa ${ }^{[a]}$, Ronaldo Gomes Gargano ${ }^{[a]}$,Fábio Parra Sellera ${ }^{\left[{ }^{[a]}\right.}$, Edlen A. Medeiros ${ }^{[a]}$,Fernando José Benesi[a], Lilian Gregory ${ }^{[a]}$, Lilian Rose Marques de Sá[b] , Fabio Celidonio Pogliani[a]

\footnotetext{
[a] Departamento de Clínica Veterinária, Faculdade de Medicina Veterinária e Zootecnia, Universidade de São Paulo (USP), São Paulo, SP, Brasil

${ }^{[b]}$ Departamento de Patologia, Faculdade de Medicina Veterinária e Zootecnia, Universidade de São Paulo (USP), São Paulo, SP, Brasil
}

*Autor correspondente e-mail: canjos@usp.br

\section{Resumo}

A descorna por ferro quente é descrita como uma das principais técnicas para inviabilizar o crescimento do epitélio germinativo dos botões córneos, prática realizada no manejo de caprinos, visando reduzir risco de ferimentos a manipuladores e outros animais. Apesar do procedimento anestésico, a descorna é uma experiência dolorosa em decorrência da extensa perda tecidual em todas as camadas da epiderme e derme. Aplicações de fototerapias com laser de baixa intensidade têm despertado interesse por apresentarem, dentre seus benefícios no tratamento de queimaduras, a reparação tecidual e analgesia. Seu mecanismo de ação se baseia na absorção dos fótons por cromóforos do tecido alvo do hospedeiro, resultando na ativação ou inibição de funções celulares, em função do comprimento de onda e dosimetria luminosa empregada. Acredita-se que a fotoestimulação das células endoteliais promova a proliferação de fibroblastos e, consequentemente, a deposição de colágeno, colaborando para maior formação do tecido de granulação e efetiva contração da ferida. Objetivou-se avaliar a aplicabilidade do laser de baixa intensidade e a qualidade da cicatrização por meio da quantificação de colágeno do tipo III no tratamento de queimaduras induzidas por descorna à ferro quente em caprinos. Para o estudo foram utilizados dois caprinos, fêmeas, Saanen, com uma semana de idade. Após tricotomia, antissepsia da região e anestesia regional com cloridrato de lidocaína 2\%, sem vasoconstritor, efetuou-se cauterização com ferro incandescente. Após a descorna, os animais foram submetidos aos tratamentos: 1) pomada cicatrizante à base de óxido de zinco, durante cinco dias, BID; 2) laser infrevermelho $(\lambda=808 \mathrm{~nm}, 100 \mathrm{~mW}, 4$ pontos, $4 \mathrm{~J}$ por ponto), durante cinco dias, SID. Para a quantificação histológica de colágeno, ao 15으 dia fragmentos cutâneos foram coletados por meio 
de punch (6mm), processados conforme técnica preconizada para picrossirius red (PR) e analisados em microscopia de luz polarizada, 400x (obj. 40x) em cinco campos sequenciais com auxílio de ferramenta de reconhecimento colorimétrico (Image- ProPlus, versão 4.5). 0 tratamento proposto com laser infravermelho apresentou maior área média de colágeno tipo III $\left(2.433,78 \mu \mathrm{m}^{2} /\right.$ campo $)$ quando comparada com a área média do tratamento à base de pomada com óxido de zinco $\left(1.971,47 \mu \mathrm{m}^{2} / \mathrm{campo}\right)$. Apesar do limitado número de animais, a dosimetria utilizada nos parâmetros propostos induziu maior produção de colágeno tipo III, possibilitando melhor qualidade na cicatrização de queimaduras e otimizando, consequentemente, o processo de recuperação tecidual por meio da fotoestimulação. Portanto, além de ser uma técnica não invasiva, foi possível demonstrar a aplicabilidade e o potencial do laser infravermelho no tratamento de lesões de queimadura após a descorna por ferro quente em caprinos, encorajando estudos futuros. 